\title{
Methodological issues on 'challenges and opportunities towards the road of universal health coverage (UHC) in Nepal: a systematic review'
}

\author{
Chhabi Lal Ranabhat ${ }^{1,2^{*}}$ and Devaraj Acharya ${ }^{3}$
}

\begin{abstract}
Challenges and opportunities towards the road of universal health coverage (UHC) in Nepal: a systematic review' is a policy review paper and we published in BMC - Archives of Public Health. Policy research is the process of conducting research, analysis of, a fundamental social problem in order to provide policymakers with pragmatic, action-oriented recommendations for alleviating the problem. The objective of this paper is to illustrate some methodological issues used in that paper.
\end{abstract}

Keywords: Universal health coverage, Systematic review, Data base, Policy review

To the editor,

\section{Context}

Nepal's commitment to universal health coverage (UHC) offers a starting point for rethinking the purpose and organization of the health system and an opportunity to introduce the quality of care agenda into policy discourse [1]. By constitution, there are three level of government with specific role: federal government makes policy, provincial government monitor the programs and local government implement health care services [2]. There are limited human resources in government health system [3], geographical difficulties [4], inequality in health service $[3,5]$, varieties of health care practice [6], limited numbers of research in health program and policy [7], there is no sufficient access for

This reply refers to the comment available at https://doi.org/10.1186/s13690020-00417-y

* Correspondence: chhabir@gmail.com

${ }^{1}$ Manmohan Memorial Institute of Health Sciences, Kathmandu, Solteemod, Nepal

${ }^{2}$ Global Center for Research and Development (GCRD), Banasthali, Kathmandu, Nepal

Full list of author information is available at the end of the article international journals and data base for researcher [8] and limited health budget in research [9] in Nepal. In this line, geographical difficulties to implement health related program, level of education of country, quality of research etc., health related to action research are limited and it is not possible to do research in full fledge way consedering publication and language bias.

It is well known that the paper 'Challenges and opportunities towards the road of universal health coverage (UHC) in Nepal: a systematic review' is primarily focused for Nepal. The objective of study was to report opportunities and possible challenges rather than number of people participated in the studies and types of studies. The policies consist of mostly, legal provision, standards, guidelines, programs and selected studies. In introduction part, there is well described about the health status of Nepal, search engines, strategies, major key words, inclusion and exclusion criteria and clear Preferred Reporting Items for Systematic Reviews and Meta-Analyses (PRISMA) follow chart have been described in methodology [10]. Likewise, results have been presented with 32 literatures in four categories and 
situations have been compared with other countries in discussion section. Such components are enough for explorative systematic review. The scope of this paper is quite limited and used resources are inevitable for English and some sorts of Nepali language and there is no possibility to use other references available in other language. Indirectly, it is the monitoring regarding the UHC situation of Nepal and resources are mostly available in PubMed, Google Scholar, Health Inter-Network Access to Research Initiative (HINARI), web pages of Nepal Governments and Google. All gray materials indexed in other sources are linked in Google and it is sufficient to cite. Indexed literatures are used, if they are extracted from available data base and not necessarily mentioned if they were not received. Some data bases have special characteristics for example, Cochrane library is popular for control trials, Embase is for biomedical and pharmaceutical and Psycolnfo is psychological research other than policy and program research. The systematic review is simply review with systematic way but it is not rocket science and available materials need to investigate carefully without bias but for the metaanalysis, there is special procedure and such format need to follow specially in clinical cases. This is a policy and program review and does not follow criteria of other articles like exploration of diseases prevalence, odds ratio and to be rigid with participants, intervention, comparison, and outcomes (PICO) strategies. This paper is more applicable for policy designers, program implementers and government authorities who are more responsible to achieve universal health coverage (UHC) till 2030 and similar countries.

Application of systematic review with creative way

Systematic review is a process of presenting previous research/data/evidence in a systematic way. It needs searching strategy of literatures, inclusion and exclusion criteria, number of included and excluded literatures, reasons for excluding and total used sources in paper. Usually, systematic review and meta-analysis is used together specially in epidemiological and clinical research [11] because those researches are more technical e.g. types of study (mostly, cross-sectional, case control and randomized control trial) and analysis of prevalence, odds ratio and PICO questions. It should be keep in mind specially for the young researchers that there is different between systematic review (SR) and meta-analysis and SR is possible without meta-analysis [12]. More importantly, implementation and action research does not necessarily to follow the reporting strategies of PRISMA guidelines. Such types of research are program design, implementation, evaluations, related policies, strategies, activities, etc. [13-15] Last but not least, SR must be used by creative model other than narrow and classical way so that coming researcher shall develop and improve with more pragmatic approaches.

\section{Application of study tools}

To assess the situation of universal health coverage in Nepal it is an explorative study, the findings have been presented in narrative way. Policy and program research are quite special and more contextual and they are liberal with methodological hegemony [16]. So, it is not pure quantitative, qualitative and combine study. The Mixed Methods Appraisal Tool (MMAT) is a critical analysis tool that is designed for the appraisal stage of systematic mixed studies; qualitative, quantitative and mixed methods [17]. MMAT compiles some quantitative and some qualitative studies. It is possible for the qualitative data to be converted into quantitative data during and/or in preparation for analysis (or vice versa) [18]. In policy review, such tool is not useful and narrative analysis is the best way. Despite the context, nature of study, data reporting and synthesis, we would clearly mention the limitation of study. Nonetheless, to prepare specific systematic review protocol, complete the review process, providing specific comments (if any) by editor and approve the manuscript have the sole right with journal.

\section{Abbreviations \\ HINARI: Health Inter-Network Access to Research Initiative; MMAT: Mixed Methods Appraisal Tool; PICO: Participants, Intervention, Comparison, and Outcomes; PRISMA: Preferred Reporting Items for Systematic Reviews and Meta-Analyses; SR: Systematic review; UHC: Universal health coverage}

\section{Acknowledgements}

Not applicable.

\section{Authors' contributions}

CR and DA jointly prepared manuscript critically reviewed but concept, configuration, draft and refining of manuscript was done by CR and both authors agreed to submit the final version of manuscript.

\section{Funding}

Not applicable.

Availability of data and materials Not applicable.

Ethics approval and consent to participate Not applicable.

Consent for publication

Not applicable.

\section{Competing interests}

The authors declare that they have no competing interests.

\section{Author details}

"Manmohan Memorial Institute of Health Sciences, Kathmandu, Solteemod, Nepal. ${ }^{2}$ Global Center for Research and Development (GCRD), Banasthali, Kathmandu, Nepal. ${ }^{3}$ Bhairahawa Multiple Campus (Tribhuwan University), Siddharthanagar, Rupandehi, Nepal. 
Received: 26 March 2020 Accepted: 2 April 2020

Published online: 29 April 2020

\section{References}

1. Sharma J, Aryal A, Thapa GK. Envisioning a high-quality health system in Nepal: if not now, when? Lancet Glob Health. 2018;6(11):e1146-8.

2. Thapa R, Bam K, Tiwari P, Sinha TK, Dahal S. Implementing federalism in the health system of Nepal: opportunities and challenges. Int J Health Policy Manag. 2019;8(4):195.

3. Tamang B, Poudel PK, Karki SJ, Gautam R. A mandatory bonding service program and its effects on the perspectives of young doctors in Nepal. Rural and Remote Health. 2020;20:5457. https://doi.org/10.22605/RRH5457.

4. Freidoony L, Chhabi R, Kim C, Park M, Kim CB. The Components of SelfPerceived Health in the Kailali District of Nepal: A Cross-Sectional Survey. International Journal of Environmental Research and Public Health. 2015; 12(3):3215-31.

5. Ranabhat C, Kim C-B, Choi EH, Aryal A, Park MB, Doh YA. Chhaupadi Culture and Reproductive Health of Women in Nepal. Asia Pac J Public Health 2015;27(7), 785-795. https://doi.org/10.1177/1010539515602743.

6. Ranabhat CL, Do YA, Ahn DW, Lee KJ, Kim CB. Changing Pattern of Complementary and Alternative Medicine in Tikapur Nepal: A Hope for Future Health. Altern Integr Med. 2014;3:153. https://doi.org/10.4172/23275162.1000153

7. Shrestha S. Challenges and opportunities of public Health Research in Nepal. Kathmandu Univ Med J. 2014;12(1):1-3.

8. Acharya BR. Dimension of rural development in Nepal. Dhaulagiri J Sociol Anthropol. 2008;2:181-92.

9. Karki D. Importance of health economics for health professionals in Nepal. Birat J Health Sci. 2018;3(1):318-9.

10. Ranabhat $C L$, Kim C-B, Singh A, et al. Challenges and opportunities towards the road of universal health coverage $(\mathrm{UHC})$ in Nepal: a systematic review. Arch Public Health. 2019;77(1):5.

11. Moher D, Tetzlaff J, Tricco AC, Sampson M, Altman DG. Epidemiology and reporting characteristics of systematic reviews. PLoS Med. 2007:4(3):e78.

12. Liberati A, Altman DG, Tetzlaff J, et al. The PRISMA statement for reporting systematic reviews and meta-analyses of studies that evaluate health care interventions: explanation and elaboration. Ann Intern Med. 2009;151(4):W65-94.

13. Wu R, Li N, Ercia A. The effects of private health insurance on universal health coverage objectives in China: a systematic literature review. Int J Environ Res Public Health. 2020;17(6):2049.

14. Yaya S, Sanogo AND. Universal health coverage and facilitation of equitable access to care in Africa: a systematic review. Front Public Health. 2019;7:102.

15. Rizvi SS, Douglas R, Williams OD, Hill PS. The political economy of universal health coverage: a systematic narrative review. Health Policy Plan. 2020; 35(3):364-72. https://doi.org/10.1093/heapol/czz171.

16. Kerrigan MR, Johnson AT. Qualitative Approaches to Policy Research in Education: Contesting the Evidence-Based, Neoliberal Regime. Am Behav Sci. 2018;63(3):287-95.

17. Hong QN, Fàbregues S, Bartlett G, et al. The Mixed Methods Appraisal Too (MMAT) version 2018 for information professionals and researchers. Education for Information. 2018;34(4):285-91. https://doi.org/10.3233/EFI180221.

18. Creswell JW, Clark VLP. Designing and conducting mixed methods research Los Angles: Sage publications; 2017.

\section{Publisher's Note}

Springer Nature remains neutral with regard to jurisdictional claims in published maps and institutional affiliations.

Ready to submit your research? Choose BMC and benefit from:

- fast, convenient online submission

- thorough peer review by experienced researchers in your field

- rapid publication on acceptance

- support for research data, including large and complex data types

- gold Open Access which fosters wider collaboration and increased citations

- maximum visibility for your research: over $100 \mathrm{M}$ website views per year

At $\mathrm{BMC}$, research is always in progress.

Learn more biomedcentral.com/submissions 